\title{
The correlation between uremic pruritus and blood lead levels in prevalent hemodialysis patients and its relation to the severity of pruritus using visual analog score
}

\author{
Sahar Mahmoud Shawky, Reeham Abdel Aziz Abdel Hamid and Lina Essam Khedr *i)
}

\begin{abstract}
Background: Pruritus is a common and often distressing symptom in patients with chronic kidney disease. Though the pathogenesis of uremic pruritus remains poorly understood, systemic inflammation has presented itself as one of the possible explanations. High blood lead levels (BLLs) have been noted to be associated with inflammation and poor nutritional status in hemodialysis patients. Our aim is to study the relation between blood lead levels and uremic pruritus. This is a cross-sectional study that enrolled 50 patients; all were on regular hemodialysis 3 times per week for at least 6 months. Patients were divided into 2 groups, group $1(n=10)$ with no pruritus and group $2(n=$ 40) with varying degrees of pruritus. Group 2 was further divided according to intensity of pruritus by visual analog score (VAS) into mild ( $n=10)$, moderate $(n=20)$, and severe pruritus $(n=10)$.
\end{abstract}

Results: There was a significant difference in serum lead levels and ferritin levels between groups 1 and 2 ( $p$ value $<0.01$ and $<0.05$, respectively). There was a statistically significant difference in serum lead levels in the groups with varying intensity of pruritus, having higher serum lead levels in patients who exhibited severe pruritus ( $p$ value $<$ 0.005) Moreover, a statistically significant relation between elevated blood lead levels and the duration of dialysis was observed in this study.

Conclusion: Uremic pruritus is a multi-factorial phenomenon, and our study showed that blood lead levels in hemodialysis patients might be associated with increased intensity of pruritus.

Keywords: Uremia, Pruritus, Hemodialysis, Blood lead levels

\section{Background}

Uremic pruritus is a common symptom of end-stage renal disease (ESRD) that affects up to $46 \%$ of hemodialysis (HD) patients. It is described as an itch that spans a large surface area of the skin, with a daily or near daily occurrence, without being associated with any primary skin lesion and without affecting certain dermatomes [1]. A higher mortality rate has been reported in

\footnotetext{
* Correspondence: Linakhedr@med.asu.edu.eg

Ain Shams University, Cairo, Egypt
}

\section{Springer Open}

๑ The Author(s). 2021 Open Access This article is licensed under a Creative Commons Attribution 4.0 International License which permits use, sharing, adaptation, distribution and reproduction in any medium or format, as long as you give appropriate credit to the original author(s) and the source, provide a link to the Creative Commons licence, and indicate if changes were made. The images or other third party material in this article are included in the article's Creative Commons licence, unless indicated otherwise in a credit line to the material. If material is not included in the article's Creative Commons licence and your intended use is not permitted by statutory regulation or exceeds the permitted use, you will need to obtain permission directly from the copyright holder. To view a copy of this licence, visit http://creativecommons.org/licenses/by/4.0/. 
$\mathrm{P}$, hypervitaminosis $\mathrm{A}$, in addition to the presence of peripheral neuropathy and chronic inflammatory conditions [3]. Furthermore, it was observed in several studies that patients with secondary hyperparathyroidism exhibited an improvement in pruritus after parathyroidectomy [4-6]. However, there was no evidence that parathyroid hormone in itself elicits cutaneous reaction when injected intradermal [7].

Exposure to lead in the general population comes from different sources in the surrounding environment, including industrial pollutants, inhalation of fumes from burning lead batteries, lead-containing paints, contaminated water from old lead pipes, cosmetics, and some hair dyes [8].. Dongre et al. observed that workers with high lead exposure in the battery manufacturing factories had high blood pressure and complained of skin itching [9]. In Kerou and So-ava, where drinking water was polluted by lead, people who consumed drinking water had various symptoms including skin itching [10].

Studies have shown that blood lead levels in patients on maintenance hemodialysis are higher than in healthy adults $[11,12]$. All this taken into consideration suggests a relation between lead contamination and pruritus. Moreover, an all-cause cardiovascular and infectionrelated 18-month mortality was higher in patients on dialysis with elevated blood lead level [13].

\section{Methods}

The aim of the study is to establish a correlation between blood lead levels and uremic pruritus.

This study is a cross-sectional study that included 50 patients with ESRD with age ranging from 18 to 65 years, who are on regular hemodialysis for at least 6 months in $\mathrm{Al}$ Agouza hospital and are receiving hemodialysis sessions three times per week, $4 \mathrm{~h}$ each session. Low flux membranes were used; dialysate was with bicarbonate-based buffer for all patients. Dialysate ionic composition $(\mathrm{Na}=136-140 \mathrm{mEq} / \mathrm{L}, \mathrm{K}=0-4 \mathrm{mEq} / \mathrm{L}, \mathrm{Cl}$ $=99-110 \mathrm{mEq} / \mathrm{L}, \mathrm{Ca}=1.5 \mathrm{mEq} / \mathrm{L}$ and $\mathrm{HCO} 3=27-39$ $\mathrm{mEq} / \mathrm{L}$ ). Patients with primary skin diseases, malignancies, end-stage liver disease (child $C$ ), hepatitis $C$ virus infection, and those with serum PTH levels above 300 $\mathrm{ng} / \mathrm{l}$, total serum calcium levels above $10.2 \mathrm{mg} / \mathrm{dl}$, and phosphorus levels above $5.5 \mathrm{mg} / \mathrm{dl}$ were all excluded from this study. We also excluded those with occupations related to lead exposure (e.g., batteries manufacture). To ensure that the patients were not exposed to lead contamination during hemodialysis, a sample from dialysis water was analyzed to ensure that lead level does not exceed the maximum allowed level of contaminants according to the ministry of health guidelines which is lead level $<0.005 \mathrm{mg} / \mathrm{dl}$.

All samples were collected before the mid-week session (Tuesday or Wednesday), samples for lead were collected pre-dialysis session from arteriovenous fistula (AVF), they were collected in EDTA tubes, and lead was measured using atomic absorption spectrometry.

We divided the patients into 2 groups, group $1(n=10)$ with no pruritus and group $2(n=40)$ with varying degrees of pruritus. The severity of pruritus was measured by visual analog scale (VAS). Visual analog scale consists of a $10-\mathrm{cm}$ horizontal line with 0 points (no pruritus) to 10 points (maximum intensity of pruritus). We used the categorization by Reich et al. [14] as a reference when classifying the VAS score. The severity of pruritus is as follows: $<4$ points was considered mild, $\geq 4$ points but $<7$ points moderate; $\geq 7$ points but $<9$ points severe, and $\geq 9$ points very severe pruritus.

$\mathrm{Kt} / \mathrm{v}$ was calculated using the Daugirdes formula. Normalized protein catabolism ratio (NPCR) was calculated using the following formula $=0.22+[0.864 \times$ (intradialytic BUN rise in $\mathrm{mg} / \mathrm{dl}$ )/intradialytic hours].

\section{Statistical analysis and methods}

IBM SPSS statistics (V. 25.0, IBM Corp., USA, 20172018) was used for data analysis. Data were expressed as median and percentiles for quantitative non-parametric measures.

The following tests were done:

1. Comparison between two independent groups for non-parametric data using Wilcoxon rank sum test.

2. Comparison between more than 2 patient groups for non-parametric data using Kruskal-Wallis test.

3. Ranked Spearman's correlation test to study the possible association between each two variables among each group for non-parametric data. The probability of error at 0.05 was considered sig., while at 0.01 and 0.001 are highly sig.

4. Diagnostic validity test: It includes:

a. The diagnostic sensitivity: It is the percentage of diseased cases truly diagnosed (TP) among total diseased cases $(\mathrm{TP}+\mathrm{FN})$.

b. The diagnostic specificity: It is the percentage of non-diseased truly excluded by the test (TN) among total non-diseased cases $(\mathrm{TN}+\mathrm{FP})$.

c. The predictive value for a +ve test: It is the percentage of cases truly diagnosed among total positive cases.

d. The predictive value for a -ve test: It is the percentage of cases truly negative among total negative cases.

e. The efficacy or the diagnostic accuracy of the test: It is the percentage of cases truly diseased plus truly non-diseased among total cases. 


\section{Results}

The study population was divided into 2 groups. Group 1 included 10 patients without pruritus and group 240 patients with pruritus. Table 1 shows the demographic data of the 2 groups including original kidney disease and co-morbidities. In our study pruritus was symmetrical in $40 \%$ of patients, localized in $30 \%$ of patients in the back and limbs, generalized in $30 \%$ of patients. All patients reported that it occurred at any time during the day. All patients with pruritus reported occasional use of antihistaminic medication, 4 patients were using regular gabapentin 100-200 mg daily.

Table 2 shows a statistically significant difference in blood lead level between hemodialysis patients with uremic pruritus and those without uremic pruritus (7.5 and $18 \mu \mathrm{g} / \mathrm{dl}$, respectively) with $p$ value $(<0.003)$. Ferritin levels were higher among patients with pruritus (mean level $563.5 \mathrm{ng} / \mathrm{ml}$ ) which was statistically significant with $p$ value $(<0.05)$. Dialysis adequacy $(\mathrm{Kt} / \mathrm{v})$ is another parameter that was better in those with no uremic pruritus ( $p$ value $<0.05)$ than those with pruritus. No statistically significant difference as regards to serum albumin, normalized protein catabolism ratio (nPCR), creatinine, urea, hemoglobin ( $\mathrm{Hb}$ ) level, total leucocytic count (TLC), corrected serum calcium, phosphorus, and PTH. Although CRP levels were higher in group 2, this was not found to be statistically significant.

When comparing patients in group 2 according to their severity of pruritus using VAS, 10 patients described their pruritus as severe, 20 had moderate and 10 patients had mild pruritus, and none of the included patients in the study scored over 9.

Blood lead levels among patients with severe pruritus were significantly higher $(p<0.01)$ than those with mild and moderate pruritus. (10, 14.5, $26 \mu \mathrm{g} / \mathrm{dl}$, respectively). Moreover, blood urea levels were higher in patients with severe pruritus (VAS score 10) more than those with mild and moderate pruritus $(p<0.05)$. Among the 3 groups, there were no significant differences as regards

Table 1 Demographic data and original kidney disease for all study population $(N=50)$

\begin{tabular}{llll}
\hline & Min. & Max. & Mean \\
\hline Age & 21.00 & 65.00 & 45.6 \\
Gender & & $N$ & $\%$ \\
& Female & 28 & $56 \%$ \\
& Male & 22 & $44 \%$ \\
Causes of renal failure & Diabetes (DM) & N & $\%$ \\
& Hypertension (HTN) & 23 & $32 \%$ \\
& Unknown & 3 & $46 \%$ \\
& Analgesic abuse & 8 & $16 \%$ \\
\hline
\end{tabular}

age, creatinine, hemoglobin, corrected calcium, phosphorus, $\mathrm{PTH}$, albumin, nPCR, ferritin, dialysis adequacy, and duration of dialysis $(p>0.05)$.

Dialysis adequacy and duration were the 2 most important and statistically significant factors associated with increased levels of lead in our study population with $p$ value $<0.05$. Blood urea level was also associated with high blood lead level with $p$ value $<0.01$. However, blood lead levels were not significantly associated with age, hemoglobin levels, phosphorus, CRP, nPCR, and serum ferritin.

An association with higher blood lead levels and higher levels of PTH was found. However, it was not found to be statistically significant.

\section{Demographic data}

Demographic data are shown in Tables 3 and 4 and Fig. 1.

Multi-regression analysis: A stepwise multi-regression analysis showing that blood lead levels together with lower $\mathrm{Kt} / \mathrm{V}$ are the most sensitive predictors for pruritus $($ F-ratio $=6.2, P<0.01)$.

\section{Dependent variable: pruritus}

\begin{tabular}{lllllll}
\hline Item & $\begin{array}{l}\text { Regression } \\
\text { coefficient }\end{array}$ & $T$ & $P$ & Significance. & $\begin{array}{l}F- \\
\text { ratio. }\end{array}$ & $P$ Significance \\
(Constant) & 1.624 & 1.148 & 0.259 & & & \\
Ferritin & 0 & 1.928 & 0.062 & $\mathrm{NS}$ & \\
Lead level & 0.038 & 5.963 & 0 & $\mathrm{HS}$ & \\
Kt/v & -0.261 & - & 0.005 & $\mathrm{HS}$ & \\
& & 3.012 & & & & \\
& & & & &
\end{tabular}

$6.3960 \mathrm{HS}$

\begin{tabular}{llllll}
\hline Cutoff point & AUC & Sensitivity & Specificity & +PV80\% & -PV \\
$>11 *$ & 0.811 & 72.50 & 80.00 & 93.5 & 42.1 \\
\hline
\end{tabular}

The cutoff point of lead level for predicting pruritus in our study was $11 \mu \mathrm{g} / \mathrm{dl}$ with specificity and sensitivity $72.5 \%$.

\section{Discussion}

Uremic pruritus or in other terms "chronic kidney disease-associated pruritus" (CKD-aP) remains a frequently bothersome symptom in patients with advanced CKD or end-stage renal disease. Our still incomplete knowledge of its underlying pathophysiological mechanisms result in a lack of effective treatment modalities [15]. The aim of our study was to find a possible correlation between blood lead level and the occurrence of uremic pruritus, in addition to a possible correlation with the severity of pruritus. 
Table 2 A comparison between 2 groups (with and without uremic pruritus) as regards laboratory data where NS = non-significant, $\mathrm{SS}=$ statistically significant, and HS = highly significant

\begin{tabular}{|c|c|c|c|c|c|}
\hline & Group 1 & Group 2 & $Z$ test & $P$ value & SS \\
\hline Creatinine (mg/dl) & Median $=6.9$ & Median $=6.9$ & -0.195 & 0.846 & NS \\
\hline Urea (mg/dl) & 103.75 & 103 & -0.303 & 0.762 & NS \\
\hline Hemoglobin (g/dl) & 10.25 & 9.7 & -1.834 & 0.067 & NS \\
\hline TLC & 8.5 & 6.25 & -1.232 & 0.218 & NS \\
\hline Corrected calcium (mg/dl) & 9.8 & 9.7 & -0.757 & 0.449 & NS \\
\hline PO4 (mg/dl) & 3.45 & 3.75 & -1.021 & 0.307 & NS \\
\hline PTH (ng/l) & 215 & 159.5 & -1.482 & 0.138 & NS \\
\hline Serum albumin (g/dl) & 3.75 & 3.05 & -1.927 & 0.054 & NS \\
\hline Duration of dialysis (years) & 4.5 & 5 & -0.356 & 0.722 & NS \\
\hline CRP & 3 & 6 & -1.322 & 0.186 & NS \\
\hline $\mathrm{nPCR}$ mg/g/day & 1 & 0.75 & -1.327 & 0.185 & NS \\
\hline Ferritin (ng/ml) & 247.5 & 563.5 & -2.195 & 0.028 & S \\
\hline Blood lead level $(\mu \mathrm{g} / \mathrm{dl})$ & 7.5 & 18 & -3.023 & 0.003 & $\mathrm{HS}$ \\
\hline Kt/v (Daugirdes) & 1.28 & 1 & -2.007 & 0.045 & S \\
\hline
\end{tabular}

A study by Palaneeswari et al. in 2012 concluded that blood lead levels were higher in hemodialysis patients than in the normal subjects, with a $p$ value of 0.000 [11]. Furthermore, Chen et al., who studied Chinese stable chronic renal failure patients, hemodialysis patients, post-transplant patients, and subjects with normal renal functions, found that lead levels were elevated in the dialysis population [16].

It was evident in our study that patients who complained of pruritus had a higher blood lead level (mean lead level $17 \mu \mathrm{g} / \mathrm{dl}$ ) than those who did not (mean lead level $8 \mu \mathrm{g} / \mathrm{dl}$ ), with $p$ value $<0.005$ ). Similarly, Weng et al., in a study involving over 100 patients with uremic pruritus, showed that higher blood lead levels were significantly associated with uremic pruritus with a cutoff point of blood lead level of $12.77 \mu \mathrm{g} / \mathrm{dl}$ [13]. Our cutoff level for predicting pruritus in this study was above $11 \mu \mathrm{g} / \mathrm{dl}$. However, we excluded from our study patients who would have had occupational lead exposure. Those patients were not excluded from the

Table 3 Correlation between patients with different degrees of pruritus and serum lead level for data using Kruskal-Wallis test

\begin{tabular}{|c|c|c|c|c|c|}
\hline & Mild & Moderate & Severe & $p$ value & Significance \\
\hline Number & 10 & 20 & 10 & & \\
\hline Age & Median $=62.5$ & Median $=58.5$ & 57 & 0.453 & NS \\
\hline Creatinine (mg/dl) & 6.75 & 6.35 & 7.05 & 0.223 & NS \\
\hline Urea (mg/dl) & 96.75 & 102.25 & 137.5 & 0.011 & S \\
\hline Hemoglobin (g/dl) & 9.75 & 9.9 & 9.45 & 0.386 & NS \\
\hline TLC & 5.25 & 6.25 & 8.5 & 0.476 & NS \\
\hline Corrected calcium (mg/dl) & 9.7 & 9.65 & 9.75 & 0.977 & NS \\
\hline Phosphorus (mg /dl) & 3.95 & 3.75 & 3.5 & 0.567 & NS \\
\hline PTH & 159 & 154.5 & 164 & 0.43 & NS \\
\hline Albumin (g/dl) & 3 & 3.05 & 3.35 & 0.435 & NS \\
\hline CRP & 3.5 & 6 & 4.5 & 0.533 & NS \\
\hline nPCR (mg/g/day) & 0.8 & 0.75 & 0.95 & 0.874 & NS \\
\hline Ferritin (ng/ml) & 440 & 787.5 & 165.9 & 0.12 & NS \\
\hline Blood lead level ( $\mu \mathrm{g} / \mathrm{dl})$ & 10.5 & 14.5 & 26 & 0.005 & HS \\
\hline Kt/v (Daugirdes) & 0.8 & 0,86 & 2 & 0.207 & NS \\
\hline Duration of dialysis (years) & 4.5 & 5 & 6.5 & 0.144 & NS \\
\hline
\end{tabular}


Table 4 The relation between blood lead level and other variables in cases, showing factors associated with high blood lead levels

\begin{tabular}{|c|c|c|c|}
\hline & $r$ (correlation coefficient) & $P$ value & Statistical significance \\
\hline Age & -0.076 & 0.647 & NS \\
\hline Creatinine (mg/dl) & 0.109 & 0.502 & NS \\
\hline Urea (mg/dl) & 0.437 & 0.005 & $\mathrm{HS}$ \\
\hline $\mathrm{Hb}(\mathrm{g} / \mathrm{dl})$ & -0.264 & 0.009 & NS \\
\hline TLC & 0.139 & 0.391 & NS \\
\hline Corrected calcium (mg/dl) & -0.05 & 0.76 & NS \\
\hline Phosphorus (mg/dl) & -0.108 & 0.507 & NS \\
\hline PTH (ng/l) & 0.189 & 0.244 & NS \\
\hline Albumin (g/dl) & 0.123 & 0.451 & NS \\
\hline CRP & -0.117 & 0.471 & NS \\
\hline $\mathrm{nPCR}$ (mg/g/day) & -0.017 & 0.916 & NS \\
\hline Ferritin (ng/ml) & -0.089 & 0.584 & NS \\
\hline Kt/v (Daugirdes) & 0.328 & 0.039 & SS \\
\hline Duration of dialysis (years) & 0.38 & 0.016 & SS \\
\hline
\end{tabular}

before mentioned study by Weng et al. which could contribute to the fact that our cutoff value for lead levels was lower.

In the current study, there was a significant difference in $\mathrm{Kt} / \mathrm{V}$ between patients with no uremic pruritus and patients with uremic pruritus. It was apparent that patients with uremic pruritus had lower $\mathrm{Kt} / \mathrm{V}$ values than those without, demonstrating that efficient and adequate dialysis might be associated with better clearance of pruritogens. These findings are in agreement with a study in 2013 which concluded that hemodialysis with the target of $\mathrm{Kt} / \mathrm{V} \geq 1.5$ and the use of high-flux dialyzer may reduce the intensity of pruritus in patients on chronic hemodialysis [17]. Urea levels,

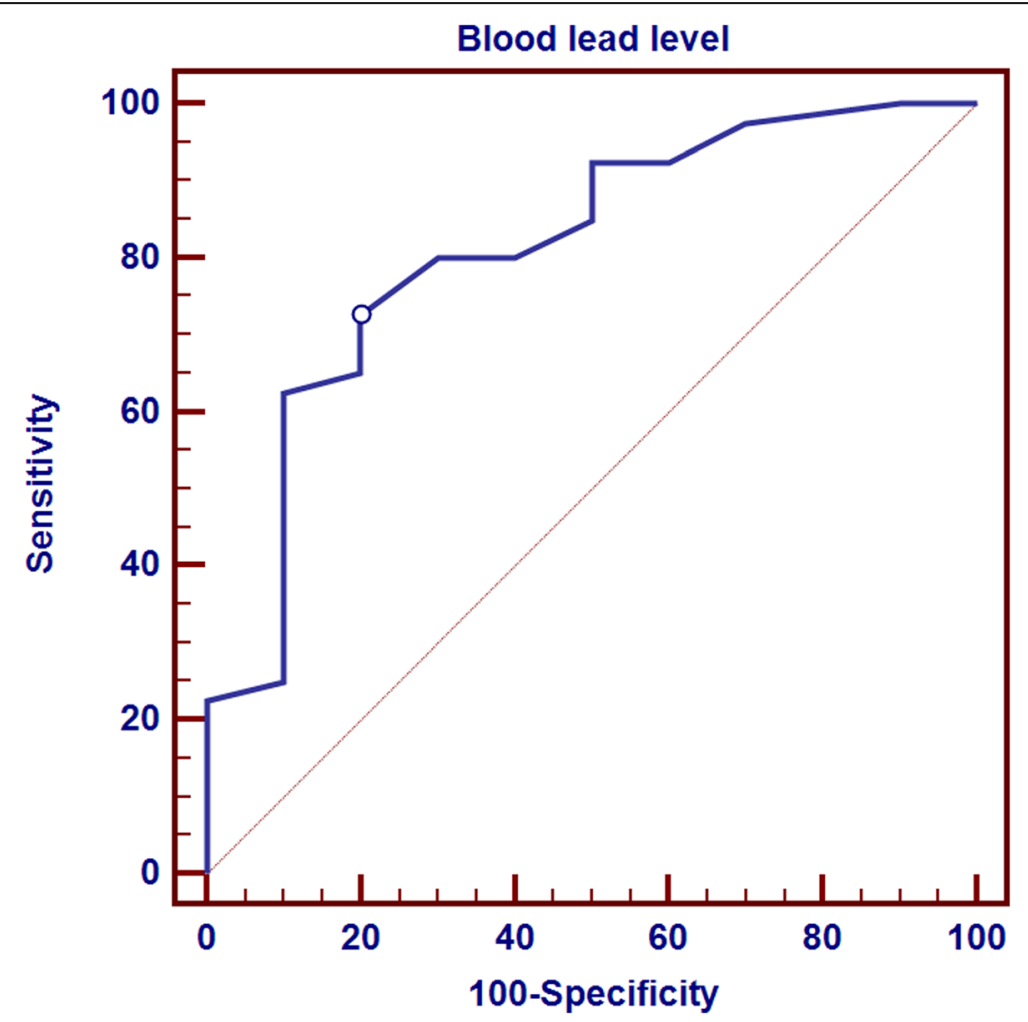

Fig. 1 ROC curve for sensitivity and specificity of BLL in predicting pruritus 
however, showed no significant difference between group 1 and group 2 in our study, which could be related to the fact that several other factors (other than urea level pre-dialysis) contribute to dialysis adequacy by $\mathrm{Kt} / \mathrm{V}$ formula, including volume of ultrafiltration and post-dialysis urea.

A study by Zucker et al. which included over 219 dialysis patients concluded that there was no relation between the occurrence of pruritus and demographic or medical parameters of the patients (including dialysis efficacy as expressed by Kt/V). In his study, however, patients used high flux dialyzers [18]. Similarly, in our study when comparing $\mathrm{Kt} / \mathrm{V}$ for different levels of pruritus severity, dialysis adequacy seems to be higher in those with more severe pruritus by VAS score. This could be due to the fact that those patients with severe pruritus had higher pre-dialysis urea than those with milder symptoms and longer duration on hemodialysis which could be the contributing factor in the severity of their symptoms and not related to dialysis adequacy.

It was also observed in the current study that there are higher levels of ferritin among patients with pruritus in comparison to those without. Ferritin is a marker of systemic inflammation, and together with CRP, it was suggested in several studies that their levels can be higher in patients with pruritus [19]. Although CRP levels were higher in group 2 with pruritus than in group 1 without pruritus, this relation was not statistically significant. Lead exposure is thought to be associated with systemic inflammation, a study reported that serum CRP levels showed a fourfold increase in the lead-exposed occupational workers compared with the control group [20].

In this study, there was no association between anemia and $\mathrm{n}$ PCR and the occurrence of pruritus. Weng et al. reached the same conclusion in their study [13]. However, in our study, it was found that blood lead levels were negatively associated with hemoglobin and nPCR. Lead exposure can be involved in the pathogenesis of anemia. Chronic lead exposure causes damage to erythrocytes by lipid peroxidation and may interfere with iron absorption in the gastrointestinal tract and impair hemoglobin synthesis [21].

Patients with elevated PTH levels above $300 \mathrm{ng} / \mathrm{dl}$, calcium over $10 \mathrm{mg} / \mathrm{dl}$, and phosphorus over $5 \mathrm{mg} / \mathrm{dl}$, were excluded from the study. The reasoning behind this was an attempt to neutralize the effects of hyperparathyroidism as an established cause of pruritus in patients on dialysis. This was evident when comparing control to cases of pruritus as PTH levels were found to be non-significant.

Moreover, we have found that the duration of dialysis and $\mathrm{Kt} / \mathrm{V}$ were the two factors that are associated with increased BLLs. The elevated BLL in HD patients may be related to the incomplete removal of lead during HD. Therefore, environmental exposure to lead, even at low levels, may increase the BLL in these patients. These results are in agreement with other randomized studies on ESRD patients and blood lead levels [21, 22]. However, a study on aluminum and lead in ESRD showed that appropriate dialysis adequacy had no effect on serum metal levels before and after dialysis [22]. Another study in 2011 stated that patients with high blood lead levels have higher Kt/V and urea values that can be attributed to the higher blood flow rate and dialysate flow rate. However, higher $\mathrm{Kt} / \mathrm{V}$ was not associated with higher blood lead levels in these patients after adjusting the related variables [23].

Weng et al. demonstrated that there was no difference in VAS score in patients with BLL $<12.77 \mu \mathrm{g} / \mathrm{dl}$ and BLL $\geq 12.77 \mu \mathrm{g} / \mathrm{dl}$, respectively [13]. Higher blood lead levels were found in this study in patients who exhibited severe pruritus using VAS score than those who had mild and moderate pruritus which was found to be statistically significant and associated also with higher urea levels. This suggests that the level of lead in blood might affect the severity of itching in dialysis patients and could be a subject for further research on this point.

\section{Conclusion}

Uremic pruritus is a multi-factorial phenomenon; our study showed that blood lead levels in HD patients might increase the intensity and have an additive role in the pathogenesis of pruritus in dialysis patients. Hence, blood lead level is positively correlated with uremic pruritus with a cutoff lead level of $11 \mu \mathrm{g} / \mathrm{dl}$ for predicting pruritus. Further studies are needed to relate lead level to the severity of pruritus and demonstrate the effect of different dialysis techniques in improving blood lead levels and severity of pruritus.

\section{Abbreviations}

ERSD: End-stage renal disease; HD: Hemodialysis; PO4: Phosphorus; Ca: Calcium; VAS: Visual analog scale; BLL: Blood lead levels; PTH: Parathyroid hormone; Hb: Hemoglobin; nPCR : Normalized protein catabolism ratio; TLC: Total leucocytic count; HS : Highly significant; NS: Non significant

\section{Acknowledgements \\ We thank the staff of the dialysis unit in Ala Agouza hospital and lab technicians for their contribution.}

\section{Authors' contributions \\ All authors discussed the results and contributed in the final manuscript. Dr.S.S conceived the idea, Dr. R A collected the data, and Dr, LK analyzed data and wrote the paper. The authors read and approved the final manuscript.}

\section{Funding}

No funding was applicable in this study.

Availability of data and materials

The data sets used during the current study are available from the corresponding author upon reasonable request. 


\section{Declarations}

\section{Ethics approval and consent to participate}

Ethics approval and consent to participate was obtained from Ain Shams University Faculty of Medicine, reference number FWA 000017585, December 2018. Written consent to participate in this study was taken from all study participants.

\section{Consent for publication}

Consent for publication was taken from all participants.

\section{Competing interests}

The authors declare that they have no competing interests.

Received: 7 January 2021 Accepted: 26 April 2021

Published online: 15 June 2021

\section{References}

1. Simonsen E, Komenda P, Lerner B, Askin N, Bohm C, Shaw J, Tangri N, Rigatto C (2017) Treatment of uremic pruritis: a systemic review. Am J Kidney Dis 70(5):638-655. https://doi.org/10.1053/j.ajkd.2017.05.018

2. Nochaiwong S, Ruengom C, Koyratkoson K et al (2017) Clinical interpretation of the Uremic Pruritus in Dialysis Patients (UP-Dial) scale: a novel instrument for the assessment of uremic pruritus. J Eur Acad Dermatol Venereol 32(7):1188-1194. https://doi.org/10.1111/jdv.14609

3. Lugon JR (2005) Uremic pruritus: a review. Hemodial Int 9(2):180-188 https://doi.org/10.1111/j.1492-7535.2005.01130.x

4. Shirazian S, Aina O, Park Y et al (2017) Chronic kidney disease-associated pruritus: impact on quality of life and current management challenges. Int J Nephrol Vascular Dis 10:11-26. https://doi.org/10.2147/IJNRD.S108045

5. Arzhan S, Roumelioti M-E, Unruh ML (2020) Itch and Ache on Dialysis: New Approaches to Manage Uremic Pruritus and Restless Legs. Blood Purification J 49:222-227 https://doi.org/10.1159/000504081

6. Zhang Y, Lu Y, Feng S, Zhan Z, Shen H (2019) Evaluation of laboratory parameters and symptoms after parathyroidectomy in dialysis patients with secondary hyperparathyroidism. Renal Failure J. 41(1):921-929. https://doi. org/10.1080/0886022X.2019.1666724

7. Stahle Backdahl M, HÄGERMARK O, Lins L-E et al (1989) Experimental and immunohistochemical studies on the possible role of parathyroid hormone in uraemic pruritus. J Internal Med 225(6):411-415. https://doi.org/10.1111/ j.1365-2796.1989.tb00104.x

8. Davenport A, Murcutt G, Whiting S (2009) Cross-sectional audit of blood lead levels in regular outpatient haemodialysis patients dialysing in north London. Nephrology (carlton) 14(5):476-481. https://doi.org/10.1111/j.1440-1 797.01087.x

9. Dongre NN, Suryakar AN, Patil AJ, Hundekari IA, Devarnavadagi BB (2013 Jan) Biochemical effects of lead exposure on battery manufacture workers with reference to blood pressure, calcium metabolism and bone mineral density. Indian J Clin Biochem. 28(1):65-70. https://doi.org/10.1007/s12291012-0241-8

10. Gilles EK, Luc K, Patient G et al (2014) Evalution of the exposure to pollutants in the drinking water of So-ava municipality using biomarkers: epidemiological study. J Biodiversity Environ Sci. 4(2):15

11. Palaneeswari MS, Abraham P, Rajan S et al (2012) Blood lead in end stage renal disease patients who were on maintenance haemodialysis. J Clin Diagnostic Res 6(10):1633-1635

12. Tonelli M, Weibe N, Hemmelgam B et al (2009) Trace elements in hemodialysis patients: a systematic review and meta-analysis. BMC Med v7: 25. https://doi.org/10.1186/1741-7015-7-25

13. Weng C, Hsu CU, Hu CC (2017) Blood lead level is a positive predictor of uremic pruritus in patients undergoing hemodialysis. Ther Clin Risk Manag J 13:717-723. https://doi.org/10.2147/TCRM.S135470

14. Reich A, Heisig M, Phan NQ, Taneda K, Takamori K, Takeuchi S, Furue M, Blome C, Augustin M, Ständer S, Szepietowski JC (2012) Visual analogue scale: evaluation of the instrument for the assessment of pruritus. Acta Derm Venereol 92(5):497-501. https://doi.org/10.2340/00015555-1265

15. Mettang T, Kremer AE (2015) Uremic pruritus. Kidney Int 87(4):685-691. https://doi.org/10.1038/ki.2013.454

16. Chen B, Lamberts LV, Behets GJ, Zhao T, Zhou M, Liu G, Hou X, Guan G, D'Haese PC, Selenium, lead, and cadmium levels in renal failure patients in China. Biol Trace Elem Res. 2009; 131(1):1-12.
17. Ko MJ, Wu HY, Chen HY, Chiu YL, Hsu SP, Pai MF, Ju-YehYang, Lai CF, Lu HM, Huang SC, Yang SY, Wen SY, Chiu HC, Hu FC, Peng YS, Jee SH (2013) Uremic Pruritus, Dialysis Adequacy, and Metabolic Profiles in Hemodialysis Patients. PLoS One. 8(8):e71404. https://doi.org/10.1371/journal.pone.00714 04

18. Zucker I, Yosipovitch G, David M et al (2003) Prevalence and characterization of uremic pruritus in patients undergoing hemodialysis: Uremic pruritus is still a major problem for patients with end-stage renal disease. J Am Acad Dermatol 49(5):842-846. https://doi.org/10.1016/501909622(03)02478-2

19. Virga G, Visentin I, Milia VL et al (2002) Inflammation and pruritus in haemodialysis patients. Nephrol Dialysis Transpl 17(12):2164-2169 https:// doi.org/10.1093/ndt/17.12.2164

20. Khan DA, Qayyum S, Saleem S, Khan FA (2008) Lead-induced oxidative stress adversely affects health of the occupational workers. Toxicol Ind Health. 24(9):611-618. https://doi.org/10.1177/0748233708098127

21. Pouresmaeil R, Razeghi E, Ahmadi F (2012) Correlation of Serum Lead Levels with Inflammation, Nutritional Status, and Clinical Complications in Hemodialysis patients. Renal Failure 34(9):1114-1117. https://doi.org/10.31 09/0886022X.2012.713281

22. Makhlough A, Shokrzadeh M, Shaliji M, et al. Comparative Analysis of Serum Heavy Metals as Aluminum and Lead Level in Dialysis Patients, Pre and post Dialysis. Res Mol Med 2014; 2(2) DOI: https://doi.org/10.18869/aca dpub.rmm.2.2.45

23. Lin JL, Lin-Tan DT, Hsu CW et al (2011) Association of blood lead levels with mortality in patients on maintenance hemodialysis. Am J Med 124(4):350358

\section{Publisher's Note}

Springer Nature remains neutral with regard to jurisdictional claims in published maps and institutional affiliations.

\section{Submit your manuscript to a SpringerOpen ${ }^{\circ}$ journal and benefit from:}

- Convenient online submission

- Rigorous peer review

- Open access: articles freely available online

- High visibility within the field

- Retaining the copyright to your article

Submit your next manuscript at $\boldsymbol{\nabla}$ springeropen.com 